19th.-Ten A.M. : Has passed a tolerable night, and is improved in every respect. The abdominal and scrotal tenderness has almost entirely disappeared; the wound in the groin is sloughy and painful. I administered a copious enema of warm water. It returned, in about half an hour, slightly discoloured and smelling very offensively.-Ten P.M. : Vomiting has been very urgent for the last two hours, and the ejecta have a fecal appearance.

20th.-Vomiting decidedly fecal and very copious. Bowels not moved. Complains of great pain about the umbilicus and left groin. The patient insists that "there is an obstruction," and prays that it may be removed.

I now began to feel that a second operation was imperatively demanded, and that in all probability we should find a knuckle of intestine had again been forced into the inguinal canal (rendered unusually patent by the recent operation) dưring the act of vomiting, no pad having been applied in consequence of the tumour left in the groin.

2lst.-Two P.M. : In the presence of Dr. Booth, Dr. Hough ton, Mr. G. O. Siddall, and two medical students, I turned tup the flaps made at the previous operation, and exposed a tumour, of the size of an egg, thickly coated with recent lymph. After scraping off some of this lymph we found the tumour to consist of two distinct parts, the upper portion being a knuckle of inflamed intestine, and the lower the testis (?). The intestine was flaccid, and overlapped the upper portion of the other tumour. I enlarged the incisions made on the previous occasion, so as to expose the whole of the inguinal canal, and found that by simply breaking down the recent lymph which connected the bowel with the canal and the internal ring, I could readily pass my finger into the abdomen. Observing this, together with the flaccidity of the bowel, I felt that the hernia was retained in the canal by the inflammatory products rather than strangulated at its neck. Partly with my finger, partly with an edgeless knife, I broke through the remaining adhesions, and then returned the bowel with the greatest facility. The gentlemen present now examined, with their fingers, the tumour left in the groin and the one in the scrotum, but without satisfying themselves as to which was really the testis. The prevailing opinion was that the testis was in the scrotum Each tumour felt as though a "cord" passed into it. The examination was merely tactile, the inguinal canal having been ascertained to contain nothing but the spermatic cord, and the communication with the abdomen to be quite free. The vomiting and sense of "obstruction" were relieved by the operation but the patient died thirty-six hours afterwards in a state of collapse, no hiccough having occurred, and the bowels not having acted.

Autopsy. - I regret that a thorough post-mortem investigation was not permitted, and that I was compelled to pledge my word that none other than the parts previously operated on should be examined, and that these should not be removed from the body. Dr. Booth assisted at the examination. To the eye and to the touch there appeared to be three testicles, two in the scrotum and one retained in the left groin. The inguinal canal and groin were now laid open. The proper in guinal canal contained, apparently, merely the cord, and was lined with a layer of recent lymph. In the groin was a tumour coated with lymph, which lymph was found to conceal a thin layer of bloodvessels and (what looked like) nerves, connected by a very fine membrane. This layer passed into the scrotum. The tumour proved to be an undescended testis, with its epididymis and cord. So far, then, with the exception of this nervo-vascular(?) membrane, the relation of parts was such as would ordinarily exist in a case of congenital inguinal hernia prior to the descent of the testis in to the scrotum, and prior to the occlusion of the processus vaginalis from the general peritoneal cavity. The testis and epididymis were quite healthy, and neither of them wounded. No doubt "the fibrous membrane" covering the testis, which I divided on the occasion of the first operation, was the peritoneum, or, to speak strictly, the processus vaginalis, thickened as a hernial sac becomes thickened when long exposed; and the filaments which I evacuated, and mis took for " coni vasculosi, "were a portion of the nervo-vascular(?) membrane which I have alluded to. I explain the reason of my not exposing the testis thoroughly at either of the operations thus:- The incision through the skin was a long one (and subsequently enlarged by a shorter one made at an acute angle). The deeper incisions were confined to the upper portion of the wound, and the intestine was reached without opening any sac of which I was cognizant. This, of course, is usual in congenital hernia. Having returned the gut thoroughly, the testis felt (through the remaining undivided layers of tissue) like a distinct tumour, as indeed it was, and
I did not feel justified in doing more than making such a puncture or (if necessary) incision as should satisfy me as to its nature. I felt satisfied that the filaments which exuded on making this puncture were "coni vasculosi," and so made no further dissection. I was wrong, and no doubt my explanation may not be considered satisfactory. I rest' satisfied with having done my duty to the best of my ability. It is impossible to place "old heads upon young shoulders" with any prospect of forming a successful combination. The testis was now removed from its position. Behind it we found a corrugated, crumpledup, thick substance, coated with fibrine. The canal became contracted immediately below the testis, so as to form a neck, through which the substance just named passed, as also the film from the front surface of the testis. The finger could be passed through this contracted portion of the inguinal canal into the scrotum, and here the canal expanded into a globalar cavity, which was filled with some membranous substance, which we presently examined. We laid open the scrotum, and exposed a glistening, oval, fibrous body, about the size, and having really some what the appearance, of a testicle. It had.a neck too, which during life, and even on tactile examination after death, passed very well for a spermatic cord. We opened this curious body, and found it to be a strong fibrous envelope, about the eighth of an inch in thickness, lined with recent lymph, and containing a globular something, also coated with lymph. This indefinite something we found to be an undeveloped, highly vascular portion of omentum, crumpled up like a veil into a roundish mass, with a process or neck passing from it through the contracted portion of the capsule; the main portion then passing behind the testis, and becoming firmly attached to the spermatic cord and to the posterior wall of the inguinal canal, whilst a thin film passed in front of the testis, and contributed to form the "coni vasculosi," which I evacuated at my first operation. The fibrous envelope became much thinner at its neck, and gradually lost itself in the lining of the inguinal canal.

Remarks. - I take it that in this case the communication between the general peritoneal cavity and the processus vaginalis lining the inguinal canal and scrotum had never been closed; that a portion of omentum passed during fotal life into this vaginal process prior to the descent of the testis; that the fibrous envelope consisted of peritoneum, fascia transversalis, and intercolumnal fascia, blended together and developed into a strong covering for the protection of the exposed portion of the peritoneal cavity and of the misplaced omentum; and that the testis remained in the groin, because its arrival in the scrotum had been anticipated and its place occupied by the protruded omentum. The canal of the processus vaginalis, when examined after death, was found to be contracted, first, at the internal abdominal ring; secondly, just above the testis; and, lastly, at the point where it formed the neck of the scrotal tumour. The contraction at the internal ring no doubt explains the reason why the hernia of the gut was not constant. I would again allude to the omentum. Is it possible that the testis passed, during fœetal life, between the layers of the great omentum? It certainly was between them when we examined the body. The appearance, too, of this omentum was very deceptive and peculiar. The thin film in front of the testis (in the groin) looked just like a number of veins and nerves connected by fine fibrocellular tissue, but coated on the external surface with soft, recent lymph. Posteriorly, this fine, vascular membrane was, as I have said, corrugated and crumpled up into a rounded substance about the size of the little finger, which expanded above and became firmly connected with the spermatic cord and the wall of the inguinal canal, and likewise expanded below so as to form the globular mass found within the fibrous capsule in the scrotum.

I must again express my regret that we were not allowed to open the abdomen; and $I$ shall be most happy to afford information on any points connected with the case which my readers may think it worth while to inquire about.

June, 1861 .

\section{ON A CASE OF VESICO-VAGINAL FISTULA.}

\section{BY EDWARD JACKSON, M.B., Sheffield.}

THE previous history of this case, which $\mathrm{I}$ have obtained from the patient herself, was as follows:-In February, 1860, after being in labour about two days, instruments were used by her medical attendant, but delivery was not effected. Severe 
hæmorrhage occurred a few hours afterwards, and she was delivered towards the close of the third day, without instrumental aid. She never passed urine through the urethra after delivery, but it constantly dribbled from her, and she lay ill for six weeks. This was her fourth confinement, and her labours had always been natural and easy previonsly.

I first saw her about three months after her confinement, and found a fistula, somewhat oval in shape, and about a quarter of an inch in its long diameter. This was somewhat obscured by being situated at the bottom of a sulcus, which proceeded from an irregular fissure, occupying the situation of the os uteri. The cavity of the pelvis was large, the vaginal walls were much relaxed, and a moderate amount of muco-purulent discharge appeared to escape from both the fistula and the fissure.

On June 5 th, 1 $\leq 60$, I proceeded to operate, having previously prepared her by suitable means. I adopted the plan recommended by Mr. I. B. Brown, and had her under the full influence of chloroform, although there was considerable difficulty in producing complete anæsthesia. The only difficulty I experienced in the operation arose from the deep and obscured situation of the fistula, and, in consequence, paring the edges oceupied me above half an hour. I inserted four iron-wire sutures, and fixed them with four leaden clamps, being perfectly satisfied with the accurate coaptation of the raw edges. There was but slight hæmorrhage during the operation, which had oceupied somewhat over an hour. I placed her in bed on her side, with instructions to give her one grain of opium every four hours, and beef-tea, with occasionally a little wine. An elastic catheter was introduced into the bladder, and the usual bag attached. On seeing her a few hours after the operation, I found that there was a copious discharge of almost pure blood through the catheter. This continued to a very considerable degree for the two following days, causing great trouble by blocking up the catheter, which required constant removal and cleansing. The urine became clear on the fourth day, and a copious muco-purnlent discharge took place from the vagina, and in the course of the following day a suspicious flow of urine oceurred, but I was doubtful whether from the vagina or by the side of the catheter.

On June 15th I removed the clamps; two were hanging loose; one was detached in introducing the speculum, and one was wanting, very probably having come away with the discharge. The parts immediately in connexion with the clamps were in a sloughy state, and urine escaped freely from the wound.

A fortnight after this date she reports having had excrucia. ting pain during and after voiding urine, and that on the previous day, after straining for a time, a hard substance came from the vagina, with immediate relief to the pain, but allowing a more copious dribbling from the vagina. This substance was unfortunately thrown away, but she describes it as a round, hard substance, as large as a horse-bean.

On August 30th I again operated upon her. The fistula was now double, the apertures being very small, and only admitting a small probe. The sulcus mentioned previously was almost obliterated, so that the parts were in a much more favourable state for operation. I seized hold of the portion between the two apertures, and cut out with one incision a circular piece, including both apertures. This, of course, made the opening as large as on the former occasion, so that I was obliged to apply four sutures, which I tixed with clamps as before. This operation occupied twenty minutes. For two days after the operation there was incessant vomiting, uncontrolled by all measures adopted to check it ; but there was no hæmorrhage, and the urine flowed freely through the catheter. I removed the clamps on September 7th, and found one of them displaced, and riding over the next one. In this situation there was escape of urine, but the rest of the wound was healed.

On Nov. 9th I again prevailed on her to undergo the operation, to which she unwillingly consented, having, as she stated, suffered but little annoyance from the fistula, and being able to retain her urine all night. On examination I found the aperture to be very small, and only capable of admitting the smallest probe. I cut out at one incision a circle including the aperture, and applied two silver-wire sutures, fixing them with a leaden shield having two perforated nipples. I remembered the vomiting on the last occasion, and feared displacement if I used the clamps. After the operation there was no vomiting, and only moderate discharge of blood through the catheter.

All went on well, and on Nov. 17th I remored the shield, and found the wound perfectly closed; but as it was not completely covered with mucous membrane, I allowed the sutures to remain two days longer.
On the 2lst she got up for the first time, and on the 24th was away from home all day, using moderate exertion.

A week later I examined the parts, and found all so well healed that I had some diffeulty in determining the seat of the fistula. I took occasion at this time to examine accurately the state of adjacent parts, which had somewhat perplexed me previously. I introduced a large-sized speculum, and found in the situation where the os and cervix uteri should have been an irregular, corrugated fissure stretching transversely across the upper part of the vagina. Instead of projecting, as in the normal state, into the vagina, this fissure gradually became unfolded as the speculum was pressed upwards, until it terminated in an irregular linear cicatrix, having a very minute perforation at its lower extremity, from which the catamenia escaped. This tissure was about an inch and a half in length, and from its upper extremity the sulcus, or rather the remains of it, proceeded in a direction obliquely forward, being evidenced by a faint cicatrix at its junction with the fissure.

It would appear from this examination that the whole of the cervix and probably some portion of the lower segment of the uterus were wanting in this case, and that in all probability the fissure and the sulcus containing the fistula were all one great opening originally.

Fern-bank, Sheffield, June, 1861 .

\section{d Mritur}

OF THE PRACTICE OF

\section{MEDICINE AND SURGERY IN THE}

\section{HOSPITALS OF LONDON.}

Nulla est alia pro certo noseandi via, nisi quam plurimas et morborum et dissectionum historias, tam aliorran proprias, collectas habere et inter se com. parare.-Mongagrr. De \$ed. et Cauts. Morb., lib. 14. Proœmium.

\section{ST. GEORGE'S HOSPITAL.}

COMPOUND COMMINUTED FRACTURE OF THE SKULL WITH DEPRESSION ; CONVULSIONS ; USE OF THE TREPHINE; MENINGITIS ; FATAL RESULT.

(Under the care of Mr. Jomsson.)

Fracture of the skall is an injury of which there is no lack of examples in our hospitals, and almost every case is pregnant with matter for study and reflection. When the mischief directly or subsequently involves the brain, the cerebral phenonomena vary considerably; but occasionally they are manifested by frequently recurring convulsions. We have seleeted three instances in which the trephine was employed; in two, convulsions were present prior to the operation, and both proved fatal; the third case, that of a boy, ended in recovery

The impression prevails amongst many surgeons that the application of the trephine is invariably unsuccessful. A very large number of patients die, not so much from the trephining as from the serious nature of the injury which both the brain and the cranium have sustained: this is well illustrated by the first two cases which follow. If, however, circumstances are very favourable, a recovery is not to be considered impossible. "But for whatever purpose trephining has been performed," observes Professor Pirrie, "the results are anything but flattering. Nélaton says that trephining has been performed sixteen times in the Parisian hospitals during the last fifteen years, and all the cases have terminated fatally. In the hospitals in London, Dublin, Edinburgh, Glasgow, Aberdeen, and other large cities in Great Britain, the mortality, although very high, is much less; and in the United States, according to Lente and Gross, the number of recoveries to the number of deaths is one to four." * In forty-five cases occurring in the New York Hospital, reported by Dr. Lente, eleven recovered. Of thirteen cases in which the trephine was used at University College Hospital, by Mr. Cooper, Mr. Liston, and Mr. Erichsen, 